\title{
An Abridgement on Curcumin Potentials for Covid-19 Treatment- A Miracle Drug?
}

\author{
Priyanka Anvekar, Manoj Kumar, Petras Lohana \\ How to cite this Article: \\ Anvekar P, Kumar M, Lohana P. An Abridgement on Curcumin Potentials for Covid-19 Treatment- A Miracle Drug? J Bahria Uni Med \\ Dental Coll. 2021; 11(3):138-139. DOI: https://doi.org/10.51985/FCQP9063 \\ - - - - - - - - - - - - - - - - - - - - - - - - - - - - - - - - \\ which permits unrestricted non commercial use, distribution and reproduction in any medium, provided the original work is properly cited. \\ - - - - - - - - - - - - - - - - - - - - - - - - - - - - - - - - - - - - - - - - - - - - - - - - - - - - - - -
}

The world was brought to a standstill by the rapid spread of Severe Acute Respiratory Syndrome Coronavirus 2 (SARS-CoV-2), responsible for COVID-19. Initially recognized in Wuhan, China, in December 2019, it was announced to be a pandemic. It is known to spread from person to person via respiratory droplets such as saliva, cough and sneeze. The infection can be established by the real-time reverse transcription-polymerase chain reaction (rRT-PCR) test on the mucosal swabs and by testing the IgG and IgM on the blood samples. Patients experiencing severe symptoms are advised to undergo computed tomography (CT) scans to rule out extensive lung involvement ${ }^{1}$

The pathophysiology of respiratory distress in SARS-CoV2 is explained by the enveloped nature of the non-segmented positive-sense RNA virus that mainly expresses various proteins, primarily the S-protein. The S-protein interacts with ACE-2 receptors present in the alveolar cells of the lungs, nasal epithelium, intestinal lining, etc. ${ }^{2,3}$ This interaction causes suppression of ACE-2 receptors, resulting in potential complications like pulmonary hypertension, acute lung injury, and lung fibrosis. While many are asymptomatic from the infection, a large spectrum of the patient population presents with fever, lethargy, headache, muscle pains, and diarrhoea. The respiratory viral infection even manifested as silent hypoxemia, respiratory distress, and multi-organ failure. ${ }^{3}$

Turmeric is extensively used in their authentic cuisine and conventional medicine. Curcumin, the primary yellow substance in turmeric, is effective against various pathogens and viruses like Hepatitis, Zika, and HIV. ${ }^{4}$ Inflammation and oxidative stress have been the primary mechanism behind the pathophysiology of a wide variety of diseases.

\begin{tabular}{|c|}
\hline $\begin{array}{l}\text { Priyanka Anvekar } \\
\text { Medical Officer } \\
\text { MGM Medical College and Hospital, India } \\
\text { Email: priyankaanvekar.pa@gmail.com }\end{array}$ \\
\hline $\begin{array}{l}\text { Manoj Kumar Menda } \\
\text { Medical Officer } \\
\text { St Johns Medical College, Bangalore }\end{array}$ \\
\hline $\begin{array}{l}\text { Petras Lohana } \\
\text { Medical Officer } \\
\text { Liaquat Institure of Medical and Health Sciences, } \\
\text { Jamshoro }\end{array}$ \\
\hline $\begin{array}{l}\text { Received: } 15-05-2021 \\
\text { Accepted: 29-06-2021 }\end{array}$ \\
\hline
\end{tabular}

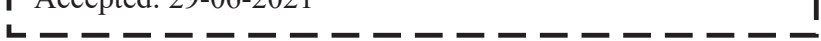

Few of the many diseases include alzheimer's disease, parkinson's disease, cancers, atherosclerosis, arthritis, psoriasis, bronchitis, asthma, allergies, whereas infections like acquired immunodeficiency syndrome (AIDS) and COVID-19. ${ }^{8}$

Curcumin is known to exhibit anti-inflammatory properties and may act as a potent agent to help fight against these diseases. The anti-inflammatory effect is mainly due to its ability to prevent the upregulation of cardinal inflammatory enzymes like cyclooxygenase-2 (COX-2), lipoxygenase (LOX), and inducible nitric oxide synthase (iNOS); these are responsible for the pathogenesis of many carcinomas and inflammatory diseases. ${ }^{9}$ Another key agent involved in the pathogenesis of inflammation is tumor necrosis factor $\alpha(\mathrm{TNF}-\alpha)$. Its effect is controlled by regulating a transcription factor called nuclear factor $(N F)-\kappa B$. (NF) $-\kappa B$ is triggered by various bacteria, viruses, stress, and other environmental factors like smoke. Curcumin may further help with suppressing inflammation by hindering the stimulation of $(\mathrm{NF})-\kappa \mathrm{B}$. Curcumin also has detrimental effects on free radicals such as reactive oxygen and nitrogen species (ROS, NS) which may favor in preventing oxidative stress. ${ }^{8}$

In the coronavirus case, curcumin suppresses ACE-2, which prevents the SARS-CoV-2 virus from targeting the cells. Moreover, the substance can stop the replication of RNA synthesis, demonstrating its antiviral properties. Few studies also suggested that it hampers the infection by binding to the molecular ligand instead of the viral proteins. ${ }^{5}$ Some studies have shown that curcumin also decreases ovalbumin (OVA), responsible for hyper-reactive airway disorders and allergen-induced broncho-constriction. Curcumin also helps in gene expression alteration, which causes cell cycle arrest in patients with pulmonary fibrosis. ${ }^{10}$ Curcumin has antiinflammatory properties, which suppress NF- $\kappa$ B activity leading to a significant reduction in the pro-inflammatory cytokines. ${ }^{2}$ Thus curcumin is beneficial in patients with chronic diseases.

Like other respiratory viruses, SARS-CoV-2 also expresses pro-inflammatory mediators, leading to the release of inflammatory cytokines causing increased vascular permeability, which can induce pulmonary edema and severe acute respiratory distress. The anti-inflammatory and immunomodulatory properties expressed by curcumin inhibit inflammatory mediators such as cytokines, potentially 
beneficial in COVID-19 patients. The anti-inflammatory property possessed by curcumin may also help in other inflammatory disorders like inflammatory bowel disease, arthritis, etc. ${ }^{11}$ Curcumin promotes cardiovascular health. Curcumin effectively improvising the cardio toxicity caused by various medications such as doxorubicin and nontherapeutic agents. Curcumin reduces oxidative stress and inflammation in the cardiac tissues by regulating and suppressing various inflammasomes. ${ }^{6}$

Apart from the anti-inflammatory effect, Curcumin has shown other beneficial effects such as anti-thrombotic by lowering serum cholesterol, which might prevent atherosclerosis and metabolic syndrome and diabetes mellitus. Moreover, Curcumin has a possible role in the homeostasis of calcium $(\mathrm{Ca})^{2+}$ which might be helpful in the prevention of ventricular arrhythmias. The anti-inflammatory effect also alleviates atrial arrhythmia. The inhibitory effect on the p300-HAT has shown improvement in animal models with cardiac failure and hypertrophic cardiac conditions. ${ }^{7,8}$

Furthermore, this significant component exhibits properties to relieve pain, abnormal body temperature, and fatigue which can be substantial in managing symptoms in patients with COVID-19. ${ }^{3}$ COVID-19 also can induce venous thromboembolism in different ways. The proposed mechanisms behind thrombus formation are activation of coagulation pathway by the released cytokines, endothelial damage, which is identified by elevated levels of von willebrand factor, systemic inflammation caused by tolllike receptor factors, activation of pro-coagulation state, hypoxia-inducible transcription factor leading to thrombus formation in hypoxic conditions, and last but not the least anti phospholipid antibodies causing immune-mediated damage and thrombus formation. ${ }^{12}$

Curcumin exhibits anti-thrombotic and anticoagulant properties by prolonging activated partial thromboplastin time (aPTT) and prothrombin time (PT) and decreasing thrombin and FXa activity could demonstrate beneficial effects in patients with COVID-19 infection. ${ }^{11,13}$

Additionally, the inclusion of other known and available vitamins and trace elements such as vitamin $\mathrm{C}$ and zinc has shown beneficial effects in augmenting the body's natural defence mechanism against COVID-19. It has also helped in the post-infection phase for many. ${ }^{2}$

In a nutshell, Curcumin exhibits anti-inflammatory and antioxidant properties, making it a promising agent against many viruses and other inflammatory diseases. Thus, it had been a significant constituent of many traditional medicines throughout many parts of the world. Many studies have helped establish that the SARS-CoV-2 virus causes cytokine surge by activating different inflammatory mediators, leading to pathological conditions such as respiratory distress, pulmonary fibrosis, and even thrombus formation. Curcumin's anti-inflammatory effect may contribute at various levels to ameliorate the inflammation in the patients with COVID19 infection, thus, acting as a potent adjuvant therapy in the treatment of COVID-19.

Authors Contribution:

Authors Contribution:

: Construct the Manuscript, References

and Detailing, Title

| Manoj Kumar Menda: Proof Read, Plagiarism and Finesse | Petras Lohana: Title, Proof Read.

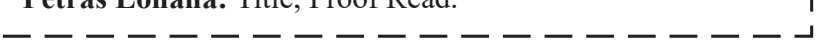

\section{REFERENCES:}

1. Valencia DN. Brief Review on COVID-19: The 2020 Pandemic Caused by SARS-CoV-2. Cureus. 2020 Mar 24;12(3):e7386. doi: 10.7759/cureus.7386. PMID: 32337113; PMCID: PMC7179986.

2. Manoharan Y., Haridas V., Vasanthakumar K.C., Muthu S., Thavoorullah F.F., Shetty P. Curcumin: a wonder drug as a preventive measure for COVID19 management. Indian journal of clinical biochemistry: IJCB. 2020;35:373-375. doi: 10.1007/s12291-020-00902-9. PMID: 32641876; PMCID: PMC7299138

3. Babaei F, Nassiri-As1 M, Hosseinzadeh H. Curcumin (a constituent of turmeric): New treatment option against COVID19. Food Sci Nutr. 2020 Sep 6;8(10):5215-5227. doi: 10.1002/fsn3.1858. PMID: 33133525; PMCID: PMC7590269.

4. Gupta H, Gupta M, Bhargava S. Potential use of turmeric in COVID-19. Clin Exp Dermatol. 2020 Oct;45(7):902-903. doi: 10.1111/ced.14357. Epub 2020 Jul 27. PMID: 32608046; PMCID: PMC7361299.

5. Zahedipour F, Hosseini SA, Sathyapalan T, Majeed M, Jamialahmadi T, Al-Rasadi K, Banach M, Sahebkar A. Potential effects of CCurcumin in the treatment of COVID-19 infection. Phytother Res. 2020 Nov;34(11):2911-2920. doi: 10.1002/ptr.6738. Epub 2020 Jun 23. PMID: 32430996; PMCID: PMC7276879.

6. Yarmohammadi F, Hayes AW, Karimi G. Protective effects of Curcumin on chemical and drug-induced cardiotoxicity: a review. Naunyn Schmiedebergs Arch Pharmacol [Internet]. 2021; Available from: http://dx.doi.org/10.1007/s00210-02102072-8

7. Wongcharoen $\mathrm{W}$, Phrommintikul A. The protective role of CCurcumin in cardiovascular diseases. Int J Cardiol. 2009;133(2):145-51

8. Hewlings SJ, Kalman DS. Curcumin: A review of its effects on human health. Foods [Internet]. 2017;6(10). Available from: https://www.mdpi.com/resolver?pii=foods6100092

9. Menon VP, Sudheer AR. Anti-oxidant and anti-inflammatory properties of Curcumin. Adv Exp Med Biol. 2007;595:105-25.

10. Aggarwal BB, Harikumar KB. Potential therapeutic effects of Curcumin, the anti-inflammatory agent, against neurodegenerative, cardiovascular, pulmonary, metabolic, autoimmune and neoplastic diseases. Int J Biochem Cell Biol. 2009;41(1):40-59.

11. Rocha FAC, de Assis MR. Curcumin as a potential treatment for COVID-19. Phytother Res. 2020;34(9):2085-7.

12. Wichmann D, Sperhake J-P, Lütgehetmann M, Steurer S, Edler C, Heinemann A, et al. Autopsy findings and venous thromboembolism in patients with COVID-19: A prospective cohort study: A prospective cohort study. Ann Intern Med. 2020;173(4):268-77. 